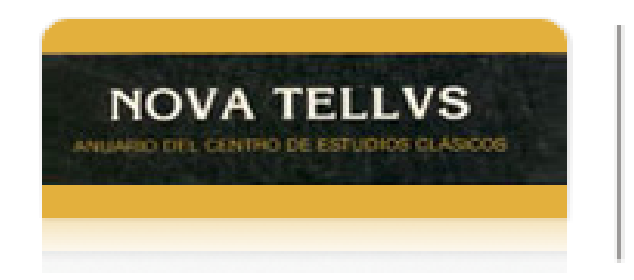

Nova Tellus

ISSN: 0185-3058

novatelu@servidor.unam.mx

Centro de Estudios Clásicos

México

Ramírez Trejo, Arturo E.

La retórica novohispana: origen, desarrollo y doctrina (siglos XVI-XVIII)

Nova Tellus, vol. 30, núm. 1, 2012, pp. 149-165

Centro de Estudios Clásicos

Distrito Federal, México

Disponible en: http://www.redalyc.org/articulo.oa?id=59128312006

- Cómo citar el artículo

- Número completo

- Más información del artículo

Página de la revista en redalyc.org

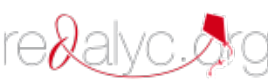

Sistema de Información Científica

Red de Revistas Científicas de América Latina, el Caribe, España y Portugal

Proyecto académico sin fines de lucro, desarrollado bajo la iniciativa de acceso abierto 


\title{
La retórica novohispana: origen, desarrollo y doctrina (siglos XVI-XVIII)
}

\author{
Arturo E. RAMÍREZ TREJO \\ Universidad Nacional Autónoma de México \\ aramirea@servidor.unam.mx
}

\begin{abstract}
RESUMEN: La retórica novohispana nace bajo el modelo retórico de la teoría aristotélica. Las circunstancias de conquista y evangelización de los pueblos indígenas favorecieron sus características epicóricas: controversia, apología y educación. Se desarrolló a partir de la teoría retórica clásica, como se constata en la cátedra y en la asamblea, es decir, tanto en la teoría como en la práctica, según las fuentes manuscritas e impresas que se conservan. El objetivo de la retórica novohispana era la persuasión; su doctrina abordaba, entre otros aspectos, la definición de la retórica, los tópicos y la estructura del discurso retórico, mismos que, sin desvirtuar el modelo clásico, adecuó a las nuevas condiciones. Sobre esto último, como se mostrará aquí, todavía hay mucho por descubrir, tanto en textos impresos como manuscritos conservados en archivos.
\end{abstract}

\section{Rhetoric in New Spain: Origin, Development, and Doctrine (16th-18th)}

\begin{abstract}
Rhetoric in New Spain was born in the wake of the rhetorical model theorized by Aristotle. The local circumstances during the conquest and Christianization of the indigenous peoples favored the development of epichoric shapes: disputation, encomium and teaching. It grew out of the rhetorical Classical theory, as is clear both from the teaching environment and the assembly. In other words, it was attested both in theory and in practice, according to the now available manuscripts and printed documents of that time. The aim of rhetoric in New Spain was persuasion and it treated subjects such as its own definition, the topics and speech structure, among other aspects. Still, without defiling the Classical model, rhetoric in New Spain adapted these subjects to the new context. Regarding the latter issue, as we will show here, there is still much research to do, both in manuscripts and printed material hold in archives.
\end{abstract}

PALABRAS ClAVE: Retórica novohispana, tradición retórica, Aristóteles.

KEYWORDS: Rhetoric in New Spain, rhetorical tradition, Aristotle.

FECHA DE RECEPCIÓN: 20 de marzo de 2012.

FECHA DE ACEPTACIÓN: 12 de agosto de 2012. 



\title{
La retórica novohispana: origen, desarrollo y doctrina (siglos XVI-XVIII)
}

\author{
Arturo E. RAMÍREZ TREJO
}

La retórica novohispana tuvo como marco de referencia la llamada Nueva España, una región del Nuevo Orbe, durante los siglos XVI al XVIII d. C. En diferentes momentos y en formas muy variadas, los estudiosos se han ocupado de cuestiones, autores y obras que atañen a esa disciplina. Entre otros, Ignacio Osorio abordó ese tópico en su Floresta de gramática, poética y retórica en la Nueva España, ${ }^{1}$ además de quienes participaron en el congreso en Perugia, Italia, sobre Diego Valadés. ${ }^{2}$ Yo mismo he escrito varios ensayos al respecto. ${ }^{3}$ En las páginas que siguen ofrezco una visión panorámica de la retórica novohispana, con cierto énfasis en el siglo XVI y retomando, como punto de partida, algunos elementos ya abordados en otros trabajos, con el propósito de llamar la atención al estudio de ese asunto tan importante en la cultura mexicana. Este artículo es, pues, un apuntamiento hacia lo que algún día pueda ser un tratado o historia de la retórica novohispana, escrito por plumas más diestras. Hay que advertir finalmente que las citas de ediciones antiguas se transcriben sin modificar su carácter original.

\section{Origen de la retórica novohispana}

Toda enunciación retórica se desarrolla en el ámbito del lenguaje y de la comunicación humana, y tendrá, por tanto, aspectos universales y particulares, como el mismo ser humano, de quien la retórica es propia. Según Aristóteles, tanto la dialéctica como la retórica gozan en forma análoga de esa universalidad y particularidad:

${ }^{1}$ I. Osorio Romero, 1980.

${ }^{2}$ Convegno Internazionale "Diego Valadés e la Rhetorica Christiana”, Università degli Studi di Perugia, mayo de 1992, cuya memoria fue publicada en C. Finzi y A. Morganti, 1995.

${ }^{3}$ A. Ramírez Trejo, 2002, 2010 y 2011. 
Ambas, en efecto - dice-, versan acerca de cosas tales, que, comunes en cierto modo, de todas es competencia conocerlas y no de alguna ciencia determinada. Por eso también todos en cierto modo participan de ambas, pues todos hasta cierto punto tienen entre manos tanto averiguar como sostener una razón, tanto defenderse como acusar. ${ }^{4}$

Y, naturalmente, de las circunstancias históricas y de la práctica, ya sea al azar ya sea en cierta forma acostumbrada, surge la doctrina retórica, como dice Aristóteles: "y ya que de ambas formas es posible, es evidente que sería posible también hacerlo con método". ${ }^{5}$ Así, los acontecimientos y las circunstancias de tiempo y lugar son el marco histórico necesario para el origen y desarrollo de una doctrina retórica.

Ahora bien, el 12 de octubre de 1492 ocurrió un acontecimiento trascendental en la historia de la humanidad: el descubrimiento del Nuevo Orbe, como lo llamaron los novohispanos. Dicho suceso y las acciones realizadas en torno al mismo fueron el marco histórico para una época de la práctica y doctrina de la retórica. De ese Nuevo Orbe hacía mención Julio II en su bulla Universalis Ecclesiae, del 28 de julio de 1508, a los Reyes de España: "Tierras no conocigas... Países ignorados, muchos Lugares, e Islas, y entre ellas una muy poblada y de mucha estimación, a la que pusieron el nombre de Nueva España”. ${ }^{6}$ Esta es una de las menciones más antiguas de dicha región. A eso se reduce lo novohispano, en el espacio, en el tiempo y en su gente, $\mathrm{y}$, por ende, también la retórica.

Es bien sabido que de los españoles llegados a la Nueva España, unos llegaron como conquistadores y otros como misioneros. Los primeros se valieron de la fuerza física y de las armas para someter a los indígenas y despojarlos de sus tierras, como consta en las denuncias que de ello hicieron los escritores apologistas de los indios, como Las Casas, en su Brevísima relación de la destrucción de las Indias, Alonso de la Veracruz, en

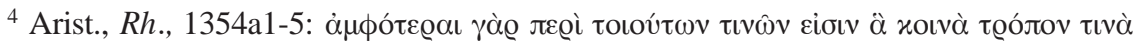

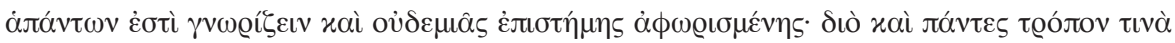

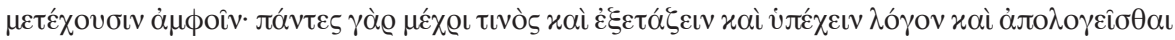

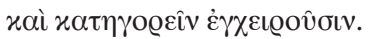

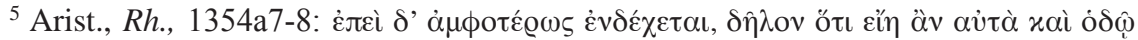

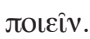

${ }^{6}$...ignotis etiam terris..., et Insulas et Loca plurima, et inter caeteras, maximi pretii, et populatissimam unam, illique Novam Hispaniam nomen imposuissent (texto y traducción de A. J. de Rivadeneyra Barrientos, 1993, pp. 410-411). 
De dominio infidelium et iusto bello, o Zapata y Sandoval, en De iustitia distributiva. Frente a esta conquista militar contrasta la labor humanitaria de los misioneros, quienes se enfrentaron tanto a las costumbres y a las disposiciones de ánimo de los indígenas como a la conducta injusta y cruel de los conquistadores, que en manera alguna era rúbrica de la doctrina de la evangelización.

Las bulas Inter caetera de Alejandro VI (1493) y Universalis Ecclesiae de Julio II (1508), bajo la doctrina del poder absoluto, concedieron a los reyes de España territorios y dominio sobre los pueblos descubiertos y conquistados, y propiciaron la situación de conflicto en el mundo novohispano. De tal manera, el lenguaje bélico de la conquista se trasladó al lenguaje dialéctico de la controversia De debellandis Indis, en la que naturalmente una de las partes fue la apologética ya mencionada. Además de la controversia y la apología, surgió también el discurso de la Evangelización, para que los misioneros instruyeran y educaran en las buenas costumbres a los indígenas, como decía Alejandro VI en su bula: "Varones virtuosos, temerosos de Dios, doctos, y expertos, para que instruyan en la Fé Catholica, y buenas costumbres a los habitantes referidos". ${ }^{7}$ Pues la evangelización no era solamente doctrinal y religiosa, sino también educación personal y social proveniente de un mundo muy diferente al de los conquistadores. Tal fue, pues, la circunstancia novohispana que dio origen a una retórica, no nueva en su naturaleza, pero sí en sus características: la retórica novohispana.

\section{El desarrollo o conformación de la retórica novohispana}

Cuando los españoles y los indígenas intentaron comunicarse mutuamente sobre el concepto de la verdad que unos y otros profesaban en torno a su propia realidad y sobre la persuasión del mensaje de sus culturas se hizo indispensable la retórica. Los indígenas carecían de una teoría retórica, pero, como escribía el franciscano Valadés en su Rhetorica christiana, "aun sin letras, sin embargo, con figuras e imágenes unos a otros se daban a conocer lo que querían". ${ }^{8}$ Los españoles, en cambio, traían la tradición

${ }^{7}$ A. J. de Rivadeneyra Barrientos, 1993, pp. 392-395: viros probos, et Deum timentes, doctos, peritos, et expertos ad instruendum incolas, et habitatores praefatos in Fide Catholica et bonis moribus imbuendum destinare debeatis.

${ }^{8}$ P. Valadés, 1579, p. 93 X: etiam si sine literis, formis tamen quibusdam, et imaginibus voluntatem suam vicissim denotabant. 
retórica de los antiguos griegos, latinos y cristianos. Debemos decir, por tanto, que en el uso de la imagen y en la enseñanza y aprendizaje de la lengua se fincó el desarrollo de la teoría y de la práctica retórica en la Nueva España.

La solemne instauración de la retórica en la Nueva España fue el 25 de enero de 1553, cuando Francisco Cervantes de Salazar pronunció el discurso de fundación de la Universidad de México y él mismo inició la cátedra de retórica el 3 de junio del mismo año. En ella, aunque resonaban la retórica de Grecia y la oratoria de Roma, seguramente ya se percibían las características epicóricas o locales, que resplandecerían tanto en los manuales como en los discursos de los oradores y de los escritores. Por lo demás, debemos advertir que la retórica novohispana propiamente la fundarían y desarrollarían los españoles, los criollos y los mestizos cultos, y muy poco los indígenas, aunque éstos no carecían de recursos retóricos. ${ }^{9}$ En el desarrollo y conformación de la retórica novohispana podemos reconocer diferentes niveles de fusión con la clásica, no en un orden cronológico, sino por su naturaleza. Esos niveles son los siguientes:

\section{La retórica clásica en la Nueva España}

Ya se dijo que los españoles tenían una doctrina y una práctica retóricas cuando llegaron a la Nueva España. ${ }^{10}$ Sus fuentes eran Platón, Aristóteles, Cicerón, Quintiliano, Demóstenes, Basilio, Crisóstomo y Agustín.

El más antiguo manual de retórica clásica que llegó a la Nueva España y que tuvo gran difusión en Europa fue el del lusitano jesuita Cipriano Soárez o Soares: De arte rhetorica libri tres, ex Aristotele, Cicerone et Quintiliano praecipue deprompti, título que ya anunciaba sus fuentes y genealogía. Fue publicado en Coimbra en 1562, unos años antes que Ecclesiasticae Rhetoricae, sive De ratione concionandi libri sex, de Fray Luis de Granada (1504-1588), publicado en 1576 (y posteriormente siempre en español), y que la Rhetorica christiana de Diego Valadés, de 1579. El manual de Soares fue el más puro exponente de la retórica clásica en el ámbito novohispano, aunque tenga ciertos matices propios, como reducir a dieciséis los veintio-

\footnotetext{
${ }^{9}$ Por ejemplo, sobre retórica náhuatl, huichol y maya en el Chilam Balam, véase J. M. Cocom Pech, "Retórica en los libros del Chilam Balam de Chumayel y del Chilam Balam de Tuzik”, en H. Beristáin y G. Ramírez Vidal, 2004, pp 73-82.
}

${ }^{10}$ Retomamos los puntos tratados en A. Ramírez Trejo, 2011, pp. 69-74. 
cho tópicos de la Retórica de Aristóteles. ${ }^{11}$ Por lo demás, su intención fue claramente evangelizadora, pues en la presentación de la obra se dirige al christiano lectori. En el proemio describe la retórica encaminándola hacia la christiana eloquentia, en la que florecieron (hac floruere) Gregorio, Basilio, Atanasio, Crisóstomo, Ambrosio, Agustín, Jerónimo, Cipriano, añadiendo en el párrafo final que:

Quien quiera imitar a tales y tan grandes varones, que cultive la elocuencia cristiana, la cual florece a partir de la preocupación y de la contemplación de las cosas divinas, del amor a Jesucristo y, finalmente, de la dedicación a las más grandes artes. ${ }^{12}$

\section{La retórica novohispana en la retórica clásica}

En un segundo momento, la doctrina retórica novohispana se inserta en la retórica clásica, como se puede apreciar en el De arte rhetorica libri tres, atribuido al jesuita mexicano Pedro Flores. Se trata de un manuscrito posiblemente de fines del siglo XVI, ${ }^{13}$ que, desde su división en tres partes, se inserta en la escuela clásica, además de que cita a los más notables autores de la retórica griega y latina. No se necesita adivinar sus fuentes, pues comienza diciendo: "Cipriano, habiendo de transmitir sabiamente los principios para adornar el discurso, los cuales comprende la retórica". ${ }^{14}$

Así pues, a fines del siglo XVI, el tratado de Cipriano Soares muestra su influencia en los retóricos novohispanos; sin embargo, el autor del manuscrito ya tiene notables diferencias y cierta tendencia hacia la retórica eclesiástica o cristiana, que, sin ser propia de la retórica novohispana, sí era su nota esencial. En efecto, en el libro I, c. 3, f 2v ss., se ocupa ampliamente de la quaestio, proposición o problema, desarrollando el esquema de la hipótesis o causa, definida e indefinida, y de la tesis o propósito, asunto este tan

${ }^{11}$ Soares, 1611, c. XIIII. Cf. Arist., Rh.,1397a7-1400b33.

12 Soares, 1611 ( $\sin$ p.): Hos tales ac tantos viros qui volet imitari, colat Christianam eloquentiam, quae ex divinarum rerum cura, et contemplatione, ex CHRISTI IESU amore, ex maximarum denique artium studiis efflorescit.

${ }^{13}$ Se trata del manuscrito 1631, localizado en el fondo reservado de la Biblioteca Nacional de México. Jesús Yhmoff, 1975, n 281, pp. 197-198, reseña el legajo de manuscritos del que forma parte el tratado.

${ }^{14} \mathrm{Ib}$., c. I, f 1v: Sapienter Cyprianus exornandae orationis principia traditurus, quae Rhetorica disciplina complectitur. 
importante en la oratoria sacra, predicación o evangelización de la Nueva España.

Asimismo, en el c. 17, f 14r ss., trata acerca del símil o comparación (De similitudine), para adornar, amplificar y confirmar, y dice: "Como del alimento así de la doctrina no hay que tomar más que lo que sea suficiente. Sin embargo, el vientre fácilmente se llena, no así la mente" (f 16v). Esta forma de argumentar es el método bíblico de la predicación, como la parábola. En el libro II no se ocupa de tópicos, y en el c. 2, ff 37r-v, se destaca que el orador debe captar la benevolencia, la docilidad y la atención de su público, como ya lo decía Las Casas:

La criatura racional tiene una aptitud natural para que se lleve, dirija o traiga de manera blanda, dulce, delicada y suave, en virtud de su libre albedrío, para que voluntariamente escuche, voluntariamente obedezca y voluntariamente preste su adhesión y su obsequio a lo que oye". ${ }^{15}$

Reconoce además la retórica como un recurso probado para la evangelización:

El predicador o maestro que tiene el encargo de instruir y atraer a los hombres a la fe y religión verdaderas, debe estudiar la naturaleza y principios de la retórica y debe observar con suma diligencia sus preceptos al enseñar o predicar, para que pueda conmover e inducir el ánimo de aquellos a quienes se propone instruir y atraer a la fe y religión cristianas. ${ }^{16}$

En el c. 13 del manuscrito, al tratar la refutación, insiste en la reprensión con ejemplos y confirmaciones, que también no es otra cosa sino el apartar del mal, y, al hablar de la argumentación, considera como parte de la colección o reunión de pruebas, la expolición (f 44r), que después explica en particular (f 45r), y que era la forma ordinaria de argumentar en la predicación, porque la proposición, después de muchas razones de toda índole, se convertía en conclusión, como ampliamente lo explica fray Diego Valadés. ${ }^{17}$ Además, considera también el argumento a partir de la Biblia o Escritura (ex divinis litteris) (f 25v ss.), y explica, en el libro III, cuando trata acerca de la elocución, que se deben evitar los necesarios neologismos en la nueva retórica, es decir, que se diga sacrum en vez de missa; Summus Pontifex en

\footnotetext{
${ }^{15}$ Las Casas, 1975, p. 71.

${ }^{16} \mathrm{Ib}$., p. 95.

${ }^{17}$ Valadés, 1579, f 269S ss.
} 
vez de Papa; vaticinatio por prophetia; sacra virgo, y no monialis; aqua lustralis, y no aqua benedicta. Y es así que, aunque Flores recomienda el lenguaje propio y elegante en la retórica, en su precepto de argumentar a partir de la Biblia aparece una característica de la nueva retórica, pues va implícita la necesidad del neologismo, de modo que en la Nueva España la retórica clásica se renovaba.

\section{La retórica clásica en la retórica novohispana}

Sin duda la más alta expresión de la retórica novohispana fue y sigue siendo el tratado del franciscano Diego Valadés, Rhetorica christiana ad concionandi et orandi usum accommodata, dedicada al Papa Gregorio XIII y publicada en Perusa (Perugia), Italia, en 1579. Fue escrita, como dice la dedicatoria: "Después de haber consultado volúmenes casi innumerables de arte retórico, editados por diversos escritores paganos y cristianos". ${ }^{18}$ Dividida en seis partes y presentando al final una síntesis de las Sentencias de Pedro Lombardo, se aparta tanto de lo clásico como del tomismo, y tiene un propósito claramente definido: la prédica y el sermón en la evangelización de la Nueva España.

Nuestra obra, escribe Valadés, al entregar esta reflexión, está en que, siempre que hayamos desarrollado una argumentación o explicado un misterio, en cuanto es posible dirijamos eso mismo que dijimos, al objetivo de nuestro oficio, es decir, a la formación en la vida cristiana o a conmover piadosamente a las almas [...] Es sobremanera útil, prosigue, que el futuro pregonero del evangelio mantenga su espíritu apegado a esto, puesto que da gran importancia, es más, es lo capital en el deber de predicar. ${ }^{19}$

Aunque parece ser una retórica puramente eclesiástica, da importancia a la dialéctica, como la retórica aristotélica: "el principal deber de la dialéctica es demostrar con una razón probable o verdadera y el de la retórica, persuadir"; y añade: "y tanto conforme al filósofo como conforme a la verdad

${ }^{18}$ Valadés, 1579, s/p: Cum innumera fere Rhetorices artis volumina, B. P., a diuersis tam paganis, quam Christianis scriptoribus edita conspexissem.

${ }^{19}$ Valadés, 1579, p. 83 F: in hac autem cogitatione danda nobis opera est, ut quoties argumentationem aliquam fuerimus persecuti, aut mysterium aliquod explicuerimus, ad officii nostri scopum, hoc est, ad christianae vitae institutionem, aut pium animorum motum haec ipsa quae diximus, quatenus fieri possit, conuertamus [...] huic futurum euangelii praeconem animum adiungere adprime utile est, vt pote quae magnum adfert momentum immo caput est in concionandi munere. 
la retórica es consiguiente a la dialéctica" ${ }^{20}$ Lo cual hay que entender con Aristóteles, cuando dice: "La retórica es antístrofa a la dialéctica" ${ }^{21}$ Cicerón, sin embargo, parece abrir el camino a la retórica de evangelización, pues dice: "óptimo orador es aquel que con el decir enseña a los ánimos de los oyentes y también los deleita y conmueve. Enseñar es un deber, deleitar es un honor, conmover es una necesidad". ${ }^{22}$

\section{4. ¿Retórica novohispana sin retórica clásica?}

Los tratados más propios y específicos de la retórica novohispana son los que se refieren a la evangelización o predicación, sin exponer propiamente los preceptos de la retórica general. Tratados como éstos ya se conocían en España en el siglo XVI por ejemplo el de fray Luis de Granada (15041588), ya mencionado. En el siglo XVIII encontramos manuales como el de fray Martín de Velasco (OSA), Arte de sermones, para saber "hazerlos y predicarlos". ${ }^{23}$ Pero ya a principios del siglo XVII se publicó el del dominico ${ }^{24}$ Velázquez, Breve instrucción y summa de retórica de predicadores para el estudio de las materias que se tratan en los sermones, y su ampliación y disposición (México en 1628). ${ }^{25}$ Su finalidad y características se perciben ya desde el apóstrofe inicial: "O sagrado oficio el de los Predicadores Evangelicos, el de los guias del pueblo para gobernarlos, los Padres para corregirlo, los Tutores para defenderlo, los Maestros para enseñarlo,

${ }^{20}$ Valadés, 1579 , p. $51 \mathrm{H}$ : Dialectices praecipuum munus est ratione probabili aut verisimili demonstrare: Rhetorices vero persuadere et tam secundum Philosophum quam secundum veritatem, Rhetorica est consequens Dialecticae.

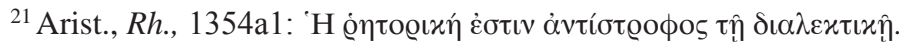

${ }^{22}$ Cic., Orat., I, 3: optimus est enim orator qui dicendo animos audientium et docet et delectat et permovet. Docere debitum est, delectare honorarium, permovere necessarium.

${ }^{23}$ Ed. Gabriel de Rivera, imp. Viuda de Miguel de Rivera, México, 1728.

${ }^{24} \mathrm{Al}$ parecer se trata de un dominico, porque en el c II, $f$ r dice: "aprovéchese de la Theología escolástica de nuestro Padre Santo Tomás".

${ }^{25}$ El volumen, que es único, aparece registrado en el CD-Fondos Bibliográficos Conventuales, CA-INAH, BNAH, Centro Nacional editor de discos compactos de la Universidad de Colima, México, 1994, clave 6728. Consta de XXXIIII capítulos y $136 \mathrm{ff}$ r/v. En este mismo $\mathrm{CD}$ se pueden encontrar muchos otros tratados y sermonarios bajo los registros de homilética y de retórica, como los sermones de Eguiara, del P. Vieyra, de Arce y Miranda. 
los Labradores para cultivarlo y los Arquitectos para edificarlo". ${ }^{26}$ Ernesto de la Torre, a propósito de Eguiara y Eguren, se expresa así de la retórica de los predicadores novohispanos: "Cualquier sermón, parto del entendimiento humano, debe imitar en cuanto pueda ser al divino; y no teniendo ese ser sino bondad, sin ella no será sermón cualquier parto del entendimiento y labios humanos; y mientras mejor fuera, será más dignamente sermón" ${ }^{27}$ Y constata cómo los sermonarios

permiten apreciar la gran estima que tuvo en la Nueva España esa forma de retórica; esa expresión literaria que a la vez era creación estética, era también el medio de formar una ideología, la cristiana, de orientar la vida diaria del hombre anónimo, estimulando sus tendencias o esforzándose por contrarrestarlas. ${ }^{28}$

Por su parte, Velázquez considera que esa retórica "puede ser en tres maneras, según tres officios que puede hazer el predicador: enseñar, alabar y persuadir". ${ }^{29}$ Además, advierte que, sin embargo: "no se quita el uso de las ciencias humanas, sino el mal uso y la demasia". ${ }^{30}$ Él mismo, en el c. IX, f 31r, discurre sobre la thesis y la hypothesis, como partes de la retórica.

Con lo anterior se puede constatar que, aun en el momento de mayor distancia, la retórica novohispana siempre guardó un estrecho vínculo con la retórica clásica, sin la cual nunca se habría estructurado, ni habría tenido el camino abierto hacia su forma tan peculiar.

\section{La doctrina retórica novohispana}

La doctrina retórica novohispana, de la que algo hemos expresado, seguía más de cerca a la institutio oratoria de los latinos que a la retórica griega; era más oratoria que dialéctica. Tal era la obra de Bernardino de Llanos, "que el padre maestro de retórica saca a la luz para comodidad y provecho de todos los estudiosos de latinidad y de retórica". ${ }^{31}$ En efecto, el Compendium Rhetoricae, de Cipriano Soarez, que incluyó en su Collectanea, ${ }^{32}$

${ }^{26}$ Velázquez, o. c., ff 1r-1v. Las citas son transcripción.

${ }^{27}$ Eguiara y Eguren, 1986, "Estudio preliminar”, p. CXIII.

${ }^{28}$ Ib., p. CXVIII.

${ }^{29}$ Velázquez, 1628, ff 98v-100r.

${ }^{30} \mathrm{Ib}$., c. IIII, f $11 \mathrm{r}$.

${ }^{31}$ I. Osorio Romero, 1980, p. 98. Osorio cita la annua de 1604, que realza la vinculación de la retórica a la latinidad.

32 B. de Llanos, 1604. 
sigue las doctrinas de Cicerón y de Quintiliano, aunque parece atender a Aristóteles, según el subtítulo de su De arte rhetorica. Diego Valadés, en el título de su Rhetorica christiana, nos da las dos características de esta retórica dirigida a los indígenas: ad concionandi et orandi. Son la contio y la oratio ciceronianas, ${ }^{33}$ pero no entendidas como arenga y discurso, sino como prédica y sermón, de ahí que Valadés no considere en su arte retórica los tres géneros de discursos clásicos, y dice "Así pues, ésta, la nuestra, se divide en Declamatoria y Oratoria". ${ }^{34}$ Por tanto, el misionero o evangelizador del Nuevo Orbe tiene una retórica muy propia, y no es un rétor o un orador común, sino un predicador.

\section{El orador}

Siguiendo la doctrina de la oratoria latina, antes que definir la oratoria o retórica, se define al orador, que en el caso de la evangelización es el predicador. Es así que se adoptó la definición de Quintiliano, inspirado en M. Porcio Catón: vir bonus dicendi peritus ("Varón bueno perito en el decir"), entendiendo como cristiana la bondad del orador. ${ }^{35}$

\section{La definición de retórica}

Con una visión oriunda y mestiza de la retórica y del orador, los novohispanos adoptaron la definición que Quintiliano diera de la retórica, cuando escribía: "Y a esta su esencia muy bien conviene la definición de que la retórica es la ciencia del bien decir ya que no puede bien decir, sino el bueno", ${ }^{36}$

Así, por tanto, la definía Valadés: "Sea, pues, la Retórica, ciencia, o facultad, o arte de ben-decir, con asentimiento de los oyentes, en cuanto es posible", ${ }^{37}$ y el jesuita Tomás González escribía: "La doctrina del ben-decir

${ }^{33}$ Cf. Cic., De or., I, 73, en donde a todos esos discursos, entre los cuales están los dos citados, los incluye in hoc declamatorio opere.

${ }^{34}$ Valadés, 1579, p. 53 T: Itaque haec nostra dividitur in Declamatoriam et Oratoriam.

${ }^{35}$ Valadés, 1579, p. 2 C. Cf. M. F. Quint., Inst. Or., XII, 1, 1, y M. P. Catón, De rhetorica, fr. 14, 1.

${ }^{36}$ M. F. Quint., Inst. Or., II, 15. 34. 2: Huic eius substantiae maxime convenit finitio, rhetoricen esse bene dicendi scientiam. Cf. Ib., 38, 2: VIII, 1, 6, 2.

${ }^{37}$ Valadés, o. c., f 50 C: Sit itaque Rhetorica, scientia, seu facultas, vel ars benedicendi, cum assensione auditorum, quoad eius fieri potest. 
se llama Retórica, retóricamente, elocuencia, Sabiduría que copiosamente habla", o bien, "Retórica es el arte o doctrina del ben-decir", y más simplemente, "Retórica es el arte de ben-decir". 38

En la traducción hemos recalcado ben-decir, porque en los textos se lee benedicere en vez de bene dicere. Esta simple unión del adverbio y del verbo en un solo vocablo expresa la visión y la intención de la retórica evangelizadora de la Nueva España, nutrida de la tradición clásica, pero sobre todo de la tradición bíblica cristiana. En efecto, ¿qué significa benedicere en la retórica bíblica? Baste leer algunos versículos de los Salmos, donde aparece

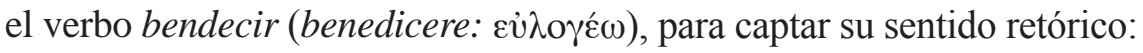

\section{SALMOS $^{39}$}

Ps 103, 2.4

Bendice, alma mía, a mi señor.

Señor, Dios mío, eres grandioso sobre manera.

Te revestiste de reconocimiento y de decoro, cubriéndote de luz como de un manto.

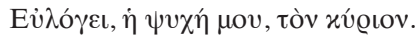

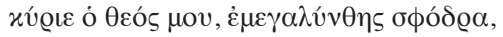

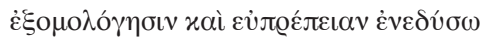

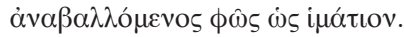

Ps 65.8

Bendecid, pueblos, a nuestro Dios.

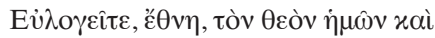

Haced que se escuche la voz de su alabanza

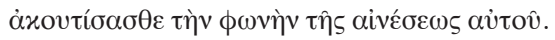

Ps 67.27

En las asambleas bendecid a Dios, al Señor desde las fuentes de Israel.

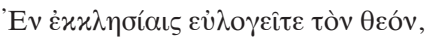

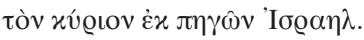

Ps 102.20

Bendecid al señor todos sus ángeles poderosos en fuerza, que ejecutáis su palabra, para que se escuche la voz de sus discursos.

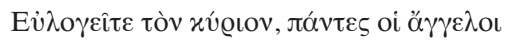
[à่นôิ,

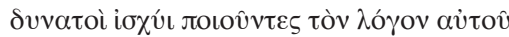

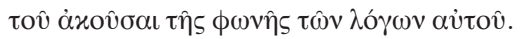

El alma, los pueblos y los ángeles bendicen, es decir, proclaman, pregonan, hacen oír la voz y los discursos del Señor, de manera que, cuando los

38 Tomás González, S. J., De arte rhetoricae libri tres y Summa totius rethoricae, respectivamente, México, 1646, c. I: Rhetorica, rhetorice, eloquentia, copiose loquens Sapientia, benedicendi doctrina nuncupatur. / Rhetorica est ars vel doctrina benedicendi. / Rhetorica est ars benedicendi.

39 Septuaginta, 1923 (TLG). Aunque ben-decir lingüísticamente está en relación directa con el latín benedicere, para el sentido retórico del vocablo latino en la Biblia se ha recurrido a los contextos griegos, porque están más cerca del original que la Vetus Vulgata latina. 
novohispanos definen a la retórica como el "arte de bendecir", entendían y daban al discurso su valor evangelizador. Con esa intención y con esa perspectiva necesariamente tenía que adoptarse y adaptarse la doctrina retórica clásica. Es, pues, claro y evidente que el discurso novohispano fue el sermón, como una forma peculiar del discurso deliberativo y del epidíctico.

\section{Los tópicos}

En cuanto a los tópicos o recursos de la argumentación, no se consideran ciertamente los veintiocho de la Retórica de Aristóteles, ${ }^{40}$ pues Cipriano Soares considera dieciséis, ${ }^{41}$ y Valadés, que los trata en la segunda parte y los llama sujetos, sólo considera nueve: Dios, Ángel, Cielo, Hombre y sus recursos (imaginación, sentido, fuerza vegetativa, elementos que se encuentran en el hombre, elementos que están a su alcance). ${ }^{42}$ Para Velázquez, los tópicos no son otros sino los sentidos de la Sagrada Escritura, que el predicador ha de hallar en ella: histórico, alegórico, anagógico o sublime y tropológico o moral. ${ }^{43}$ El único que trata la verdad, como fundamento último de la retórica, es Valadés; y ésta es la verdad teológica:

es la verdad a cuyo conocimiento se puede uno adherir explícita o implícitamente y es necesaria para la salvación a quien tiene uso de razón y la aprehende. No se adquiere en la Escritura, pero de ella puede deducirse en consecuencia necesaria. ${ }^{44}$

\section{Las partes del discurso}

Y en cuanto a las partes del discurso, Velázquez, en su Breve instrucción, señala:

Proposición, "consideracion o conclusion que se ha de prouar (autoridad, escrituras, sentencias de santos y dichos de philosophos)".

${ }^{40}$ Arist., Rh., II, 23, 1397a7-1400b33.

${ }^{41}$ Soares, o. c., c. XIIII. Cf. n. 11.

${ }^{42}$ Valadés, 1579 , p. 56 F ss.: Subiecta, quae plerique locos seu terminos appellant [...]

${ }^{43}$ Velázquez, 1628 (véase notas 11 y 35).

${ }^{44}$ Valadés, 1579, p. 64 PQR: veritas theologica est veritas cuius notitia adhaesiva necessaria est ad salutem explicite vel implicite habenti usum rationis et eam aprehendenti. Quae sub hac verborum forma non habetur in scriptura: sed ex eis potest deduci in consequentia necessaria. 
Autoridad, textos de la Sagrada Escritura.

Símil, también de la Escritura, "quando mucho dos o tres juntos".

Figura, del Antiguo testamento, "en el sentido moral o en cualquiera otro de los que vsa la Yglesia".

Confirmación, de la Sagrada Escritura, "siempre se ha de citar la edicion Vulgata".

Reprehension, "requiere mucha prudencia no diziendo palabras descomedidas", es "una cirugia donde sirue el hierro y fuego que lastima, corta y quema, conforme a la necesidad que ay". ${ }^{45}$

El manuscrito 1619 de la Biblioteca Nacional de México, Rhetorica christiana, de José Jiménez, sólo considera: salutaciones, proposiciones, conceptos e ideas, salutaciones. ${ }^{46}$ Evidentemente, el discurso se estructuraba de acuerdo al auditorio y a la temática, y siempre con una finalidad bien definida dentro del oficio del misionero evangelizador o predicador.

\section{A manera de conclusión}

Baste lo dicho, aunque sumariamente, para que tengamos bien claro que de la circunstancia novohispana se originó la retórica novohispana con un desarrollo, una estructura y unos elementos bien definidos para la evangelización de la Nueva España, pero al mismo tiempo las cuestiones esbozadas y los autores citados son sólo apuntamientos hacia investigaciones más amplias.

\section{BIBLIOGRAFÍA}

\section{Fuentes}

ARISTÓTELES, Retórica, introducción, traducción y notas de Arturo E. Ramírez Trejo, México, UnAM, 2010 (Bibliotheca Scriptorum Graecorum et Romanorum Mexicana).

Cato, M. Porcius, De rhetorica, M. Catonis praeter librum De re rustica quae extant, ed. H. Jordan, 1860.

Eguiara y Eguren, José Juan, Bibliotheca mexicana, edición preparada por Ernesto de la Torre, México, unam, 1986.

Flores, Pedro, De arte rhetorica libri tres, ms. 1631 en el Fondo Reservado de la Biblioteca Nacional de México (fines del siglo XvI). Cf. Jesús Yhmoff, Catálogo de obras manuscritas en latín de la Biblioteca Nacional de México, México, UNAM, 1975, nº 281, pp. 197-198.

\footnotetext{
${ }^{45}$ Velázquez, 1628, ff 16r-19r.

46 José Jiménez, ms. 1619.
} 
GRANADA, fray Luis de, Los seis libros de la rhetórica eclesiástica o de la manera de predicar, escritos en latín vertidos al español, Barcelona, Juan Solis y Bernardo Pla, 1770 || Libri sex ecclesiasticae rhetoricae sive de ratione concionandi, Pedro Jos de Esquerro, Lisboa / Pamplona, 1576-1577.

JiMÉnEZ, José, Rhetorica christiana, ms. 1619, en el Fondo Reservado de la Biblioteca Nacional de México.

LAS CASAS, fray Bartolomé de, Del único modo de atraer a todos los pueblos a la verdadera religión, ed. de A. Millares Carlo y L. Hanke, México, Fondo de Cultura Económica, $1975^{2}$.

Llanos, Bernardino, Breve rhetoricae compendium, en Illvstrivm Avtorvm Collectanea, México, Henrique Martínez, 1604.

Quintilianus, M. Fabius, Institutionis oratoriae libri duodecim, vols. 1-2, ed. M. Winterbottom, 1970.

_, Institutio oratoria, edición en línea: http://www.intratext.com/y/LAT0332. HTM.

Rivadeneyra Barrientos, Antonio Joachin, Manual Compendio del Regio Patronato Indiano, edición facsimilar, José Luis Soberanes, México, Editorial Porrúa S. A., 1993.

Septuaginta, vol. 2, $9^{\text {th }}$ ed., ed. A. Rahlfs, Stuttgart, Wörttembergische Bibelanstalt, 1935. SoARES, Cipriano, De arte rhetorica libri tres, Olysiponae (Lisboa), Antonio Alvarez, 1611.

_, Breve rhetoricae compendium, en Illvstrivm Avtorvm Collectanea, México, Henrique Martínez, 1604.

Thesaurus Linguae Graecae (TLG), Irvine, University of California.

VAlADÉs, fray Diego, Rhetorica christiana, Perugia, 1579. Edición facsimilar bilingüe Retórica Cristiana, introducción y traducción de varios autores, México, Fondo de Cultura Económica, 1989.

VELÁZQuEZ, Domingo, Breve instrucción y summa de retórica de predicadores para el estudio de las materias que se tratan en los sermones, y su ampliación y disposición, México, 1628.

\section{Estudios}

BERISTÁIn, Helena y Gerardo Ramírez Vidal (comps.), La palabra florida . La tradición retórica indígena y novohispana, México, unAM, 2004 (Bitácora de Retórica 19).

FINZI, Claudio y Adolfo Morganti (eds.), Un francescano tra gli Indios. Diego Valadés e la "Rhetorica christiana", Rimini, Il Cerchio, 1995.

OSORIO ROMERO, Ignacio, Floresta de gramática, poética y retórica en Nueva España (1521 - 1767), México, unam (Cuadernos del Centro de Estudios Clásicos 9), 1980.

Ramírez Trejo, Arturo, "Fuentes para el estudio de la Retórica Novohispana", en Jornadas Filológicas 2001, México, UNAM, 2002, pp. 67-75.

_, "El discurso retórico novohispano", en Pensamiento Novohispano 11, Toluca, Universidad Autónoma del Estado de México, 2010, pp. 13-22. 
_, “Retórica de la evangelización”, en Pensamiento Novohispano 12, Toluca, Universidad Autónoma del Estado de México, 2011, pp. 29-37.

Yнmoff, Jesús, Catálogo de obras manuscritas en latín de la Biblioteca Nacional de México, México, UNAM, 1975. 
